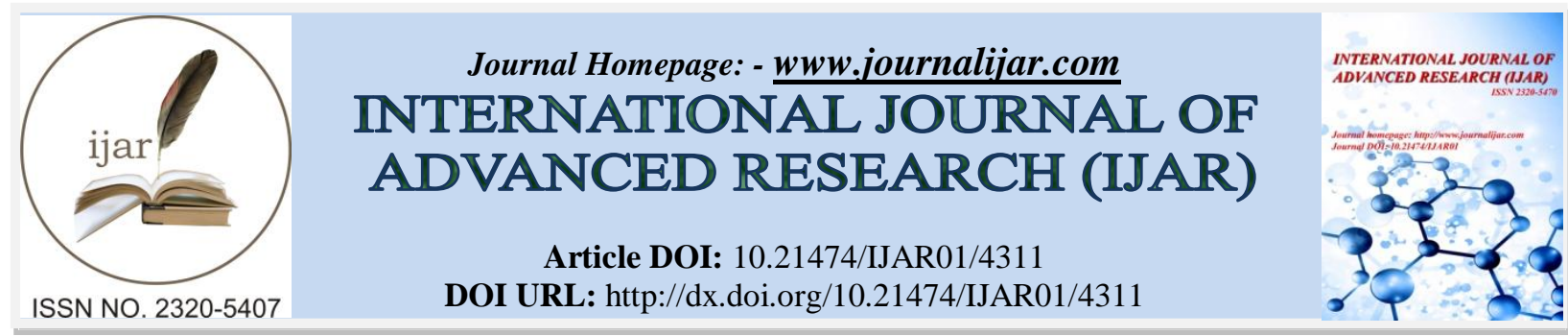

RESEARCH ARTICLE

\title{
RESEARCH CULTURE IN COLLEGES OF ERSTWHILE DODA DISTRICT OF J\&K: SIGNIFICANCE AND CHALLENGES
}

Hakim Singh.

Department of Public Policy and Public Administration, Central University of Jammu, Jammu \&Kashmir, India.

\section{Manuscript Info}

\section{Manuscript History}

Received: 21 March 2017

Final Accepted: 27 April 2017

Published: May 2017

Key words:-

Information Society, Research Culture,

Quality Education, College

\section{Abstract}

A culture of research provides a supportive context in which research is uniformly expected, discussed, produced, and valued. Research culture must not remain limited to the Universities and the institutions that are mainly established for the conduct of research, but it has to be at all those places where people have to deal with the socio, economic and educational issues. This paper explored the importance of research activity in rural colleges of Jammu province in Jammu and Kashmir. It examined how research activity was mostly lacking in the higher educational institutions in the districts-Kishtwar, Doda and Ramban. It investigated the significance of research culture in these colleges to contribute into the development of professional staff and area of knowledge within the current globalised world. Research culture can play a vital role in the development of students, teachers and environment. Therefore, an important relationship needs to be developed between continuous research activity and quality education in the colleges. For instance, the process of research can bridge various gaps in an educational setting at any level of teachinglearning process- reform in syllabus, methods of teachings and teacher-student relationship. Major problems of impeding research in the colleges and conditions affecting the research performance were indicated and highlighted. The paper focused on the research lag and passiveness in these remotest colleges where hardly any attempt had been made to use the ICT in delivering various services to the students. The lack of academic and research culture has affected overall educational system in these places. Every year, majority of students from the colleges were incapable of continuing their further education due to lack of academic and research culture in the institutions. Research culture not only affects the quality of teacher but also the quality of student in a particular institution. Therefore, the paper ends with some suggestions in which researcher focused upon values and arrangements to be made by the educational authorities to create an academic/research situation for the all round development of personality of a student as well as a teacher in a present internet and information society.

Copy Right, IJAR, 2017,. All rights reserved. 


\section{Introduction:-}

There has been an immense demand of research activity to establish the research culture in the colleges to make teaching learning process effective, modern, inclusive and participatory. Due to lack of research culture in the colleges in general and GDC Kishtwar, Ramban and Doda in particular, the educational process has been badly affected. There is a deprivation among the students as well as teachers about the importance of unavoidable relationship that exists between a research activity and the process of teaching learning process. For instance, both the processes are interrelated, complementary and supplementary to each other to achieve the certain basic goals in both respective areas of study. One is an activity of enquiry and building new concepts, theories and second is application of the same which has been researched and verified to shape the human personality. Without research activity the gap between old and modern educational values is very difficult to bridge. And without research culture both research activity as well as process of teaching learning is difficult to continue and progress. Both demand research culture to get flourished and in turn also contribute to shape it.

On the other hand, the literature reviewed by the researchers also highlighted that institutions and units that have traditionally focused effective teacher community contact with students as a criterion for success are looking to develop culture of research and faculty research production (Evans, Linda, 2007); A culture of research gave a supportive environment in which research was uniformly expected, discussed, produced, and valued (Hanover Research, May 2014) and it played a vital role in reshaping the teaching learning process (Huitt, W. (2003).

On the basis of review of related literature it can be inferred that studies had laid stress upon the type of environment that leads to research exercise among teaching staff of colleges. But none of the scholars were found interested in researching on area of research culture in the colleges in Jammu and Kashmir. There is a research gap in the literature related to research culture and its relevance for colleges.

Therefore, the current study was aimed to explore the significant connection between research culture, research activity and process of teaching learning process. A culture of research provides a supportive context in which research is uniformly expected, discussed, produced, and valued. Research culture must not remain limited to the Universities and the institutions- which are mainly established for the conduct of research. It has well contribution for all the places where people has to deal with the socio, economic and political issues and above all with teaching learning process. Therefore, the study explored the importance of research activity in rural colleges of Jammu province in Jammu and Kashmir. It described the significance of research culture to these colleges to contribute into the development of professional staff and area of knowledge in the era of globalised world. Research culture can play a vital role in the development of all three important elements of an education system-students, teachers and environment.

\section{Research Methodology:-}

The current study was based on the secondary as well as primary data, in secondary; data have been collected from various articles, journals and published documents. So far as the primary data and information is concerned, to have an insights in the various problems being faced by students and teachers in the colleges, the researcher interviewed some teaching faculty member and students from each subject of main streams of three colleges namely Government Degree College Kishtwar, Government Degree College Doda and Government Degree College Ramban through simple random sampling. It also included data collected from the official websites of selected colleges of Jammu province in J\&K.

A look at the Table No.1 highlights the sample size (of different faculty members and students) selected from three colleges in Jammu province in $\mathrm{J} \& \mathrm{~K}$. It is clear from the table that an equal representation of teachers as well as students has been made from each subject of two main streams from the colleges. Various techniques like questionnaire and discussion methods were used to complete the study. On the basis of which results were drawn and interpreted.

\section{Concepts And Discussions:- (Research And Research Culture)}

Research is a systematic investigation into and study of materials and things to establish the facts and reach at new conclusions. It is an endeavor to discover new or gather old facts by the scientific study of a subject or by a course of critical investigation. It is a systematic answer to a question or a systematic solution to a problem namely social, political, economic and educational. It is an expansion of already existing knowledge and a continuous search for 
truth which is not ultimate/static but a dynamic and continuously unfolding in nature. Research is a pattern forming a unity within a larger structural whole embracing the systematic generation of new knowledge, development of new ideas and experiment with new techniques.

At first level, these activities communicate student learning and give an intellectual environment for engaging in knowledge transfer. At second, it is Learning and Teaching. It explains a body of ideas, informed by available research and introduces habits of inquiry that reflect the provisional nature of knowledge. And finally, it is knowledge transfer. It includes various aspects of interaction between academia and the wider society - from the way public intellectuals use media space to participate in debate, to policy work for government, industry and communities, to contract research and education services, and to the complex and risky work of creating business ventures to distribute new knowledge:

1. Research is the basis of how a college education works;

2. It is the intellectual nerve system of teaching staff in an institution;

3. It is the fundamental support of our teaching and learning process and

4. It is a backbone for a particular community.

\section{Significance of Research Activity and Culture for the Colleges:-}

Research culture is an environment where research grows and multiplies. It reflects the values, ideals and beliefs about research within an organization, an institution and society. Various aspects related to significance of the research culture/research activity that should have presence in the colleges are summed up as follows:

1. There is a great role of research culture/ research activity to cope up with an explosion of knowledge and ideas and in expanding the existing knowledge with the active efforts of both teachers as well as students by getting engaged into research and brainstorming exercises in the colleges;

2. To bridge the gap between education imparted in the college and situation faced in real life, research culture has a significant role to prepare the students for real life situation-political, social and economic;

3. It can bridge a communication gap between teachers and students by their active and collaborative engagement in completing any research related tasks;

4. It can overcome the cramming based learning among the collegiate by providing them a platform for intensive and comprehensive studies;

5. It will inculcate the critical, scientific and rational thinking among the students due to their active participation into certain real life situations under the process of research;

6. It will also narrow down the gap between traditional as well as modern value systems. For instance, the research culture plays a vital role in shaping the curriculum and syllabus in accordance to modern technology and developments. The culture may be useful to inform about the new inventions, discoveries and innovations about the education at various spheres;

7. It can prepare the students for self education and self study or research in the future. It will also train them for university education which demands more comprehension power to grasp the ideas;

8. The culture/ activity can also develop an interest among the students for academics which otherwise they often lack for various reasons. The research culture can build confidence among them to take the decision for such fields (Academics, Research, Writing, Teaching etc.) as their career;

\section{Results:- (Challenges and Constraints)}

During the field visits, it was observed that all the faculty members and students had faced number of problems in their respective colleges so far as research culture and research activity is concerned. A few to mention are as under:

1. Lack of Infrastructure: There was a lack of proper infrastructure and facilities required for establishing the research culture and research activity in the colleges. The most important facility that lack in the institutions was well furnished library and internet facility.

2. Lack of Permanent Teaching Staff: Due to various geographical and political reasons staff with having a good experience and research background was hardly willing to serve the colleges situated in these remote districts.

3. Personality of Principals of the Institutions: The overall behavior of a head can play a vital role in transforming the life of both students as well as teachers in an institution but the experience of the respondents talked about the inconvenience and passive attitude of the heads towards creating a favorable conditionsresearch culture and research activity to make teaching learning process effective. 
4. Ego of Heads of Departments: Besides the unfavorable attitude of Principals, an attitude of head of the subjects also plays a significant role in deciding the fate of an institution/subject as many of heads controlling the different subjects were found less interested and motivated to empower themselves as well as the students due to their feeling of self supremacy within the institution respectively.

5. Absence of Progressive Student's organizations: Progressive Student's organizations can be termed as blood of any discourse in an institution. These create an atmosphere of contestation, representation and motivation to direct everyone towards the progress and development of an idea that need a relevant atmosphere to get flourished. But in all the colleges an absence of such organizations could be felt which blocked all the channels of questioning/criticality towards the lack of proper environment for learning in the institutions. One of the organizations found in some institution was only a puppet in the hands of some political party. It was not equipped with any idea of merit of research culture to the colleges.

6. Faulty Process of Recruitment: Quality of teacher depends on his regular and continuous habit of searching as well as researching the things- a truth which is unfolding and has many aspects demands a continuous exercise of research activity to build the research culture also. Due to faulty system of recruitment in the state in general and selected colleges in particular, teachers were found totally inactive in doing research or building the culture. The teachers had been selected on the basis of their score cards rather than research or intellectual capacity.

7. Absence of Equal Pay for Equal work: Due to absence of equal pay for equal work in the colleges contractual teachers were found less interested in any activity outside merely delivering their lectures. Colleges were largely run by contractual teachers and hardly get their full/complete wages for their service to the institutions. This affected the overall atmosphere of the institutions.

8. Location of the Colleges: Though these colleges are neither too old and nor new in origin but their location in less developed areas of the province had affected the life of a student as well as a teacher very badly. Both had less exposure and platform to perform effectively towards research culture and the related activities in the campuses.

9. Principle of Hierarchy: The principle of Hierarchy (Communication gap) found among teachers as well as between the teacher and a student affected the growth of academia in the colleges mostly. Due to inferiority/superiority complex, both of them hardly interacted with each other outside the classroom. The interaction was very less within the class room also. For instance, there was no space for debate and questioning-answering/discourse exercise in the class room usually.

10. Publications: This consists of the quality and quantity of research articles, papers and books produced by the faculty members in the colleges. This is evident in the number of published researches in local and international journals, awards attained by faculty, and patents, among others, a very least interest was found among the teachers for research- paper presentation as well as publication. There was hardly any research work done for the sake of research. The activity sometimes noticed was only for the sake of getting jobs in the universities.

\section{Suggestions:-}

In order to create and establish 'Research Culture' and 'Research Process' in educational institutions (colleges) there must be focus on some arrangements to be made for making the teaching-learning process effective. And in this only teaching faculty can play a vital role. The steps to achieve such objectives are:

1. Writing of dissertation in the last semester of the graduation courses should be introduced in the syllabus. The topic for the writing should include burning issues of the surrounding society;

2. A research experienced fellow must be recruited to play a main role in conducting the research activity in each and every department or subject. The person will be responsible for all guidance and counseling in the sphere;

3. Conducting or organizing seminars, conferences and workshops related to different themes may also contribute to research activity. It will also build the rational outlook and research attitude for learning among teachers as well as students;

4. After the completion of P.H.D courses, research scholars must be deputed and engaged in the colleges for their sixth month's internships to guide the undergraduate students in research activity. And during the internship they must be paid equivalent to college teachers with HRA allowance.

5. A special funding must be provided for all research related activities to the institutions to meet various related needs- infrastructure, events and man force.

6. There must be an exchange of ideas and thoughts among teachers and students of different colleges to quench the thirst of exposure and diversified experiences. In this regard an inter-college visit of teachers and students must be made regularly. It should provide an opportunity to exchange the teaching learning settings to both students as well as teachers. 


\section{Conclusion:-}

At last, it can be concluded that the Research culture is not only relevant for universities or the institutions specifically established for the purpose of research activity but for all places where teaching-learning process takes place. It is significant for all spheres of learning in general and at colleges in particular to establish a quality education. In addition to research culture and its relevance for an educational setting (colleges), the current study explored various loopholes in the college education due to neglect of research culture and related activities in selected institutions. The institutions lacked various basic facilities to establish the type of culture that could have produced the students for higher studies-knowledge specialization or research. Various factors which contributed towards the absence of research activity/culture in these institutions can be compiled into three broad categorieslack of infrastructure, administrative inefficiency and faulty curriculum. All these elements collectively had brought a disaster to the education system of these districts. For instance, in human, the current and upcoming generations will be the most sufferers due to type of knowledge lag that exists in these institutions. Moreover, due to lack of research culture in selected colleges, the institutions were unable to build/train the students for modern globalized, technological and positive life/world due to application of traditional education policy. On the other hand, there is a lot of scope to eradicate such drawbacks with incorporating the modern education/learning culture in higher education in general and in these colleges in particular.

\section{References:-}

1. Cheetham, Andrew. "Growing a Research Culture". University of Western, 2007.

2. Acosta, R.M. Salazar Clemeña, and S.A. Almonte. "Developing Research Culture in the Philippines Higher Education Institutions: Perspectives of University Faculty”. UNESCO FORUM, 2007.

3. Evans, Linda. "Developing Research Cultures and Researchers in HE; The Role of Leadership" University of Leeds, 2007.

4. HANOVER Research, www.hanoverresearch.com, March, 2004. 26 May 2017.

5. Hill, Robin A. "Establishing and Sustaining a Research Culture". Waikato Institute of Technology, 2002.

6. Huitt, W. (2003). A Transactional Framework of the Teaching/Learning Process, Educational Psychology Interactive, Valdosta, GA: Valdosta State University. Retrieved 25 May 2017 from http://www.edpsycinteractive.org.

7. Kumar, Ranjit. (2005). Research methodology: A Step by Step Guide for Beginners. New Delhi: Sage Publication Pvt. Ltd, 2011, pp.1-6.

\section{Annexure:-}

Status of Colleges in Research Culture:-

Table No. 1:- Status of Research Culture in the Selected Colleges

\begin{tabular}{|c|c|c|c|}
\hline \multirow[t]{2}{*}{ Indicators of Research Culture } & \multicolumn{3}{|c|}{ Colleges } \\
\hline & GDC Kishtwar & GDC Doda & GDC Ramban \\
\hline API based Promotions of Teachers & No & No & No \\
\hline Research Fund received & No & No & No \\
\hline Internet Facility & No & No & No \\
\hline Research Body & No & No & No \\
\hline Access to Journals/Periodicals within College & No & No & No \\
\hline Research Courses & No & No & No \\
\hline Research Faculty & No & No & No \\
\hline Discussion Method within Classroom Teaching & No & No & No \\
\hline Conferences and Seminars held & No & No & No \\
\hline Student's organization & Yes (1) & No & No \\
\hline
\end{tabular}

Source: Field Survey (2016) 
Profile of Respondents:-

Table No. 2:- Total Number of Respondents Interviewed

\begin{tabular}{|c|c|c|c|c|c|c|c|}
\hline Colleges & \multicolumn{2}{|c|}{ Streams } & \multicolumn{2}{c|}{ Faculty Members } & \multicolumn{2}{c|}{ Students } & Total \\
\hline GDC Kishtwar & Arts & Sciences & 3 & 3 & 5 & 5 & 16 \\
\hline GDC Doda & Arts & Sciences & 3 & 3 & 5 & 5 & 16 \\
\hline GDC Ramban & Arts & Sciences & 3 & 3 & 5 & 5 & 16 \\
\hline \multicolumn{2}{|l}{ Total } & $\mathbf{9}$ & $\mathbf{9}$ & $\mathbf{1 5}$ & $\mathbf{1 5}$ & $\mathbf{4 8}$ \\
\hline
\end{tabular}

Field Survey (2016)

Questionnaire:-

Table No.3:-Perceptions of Respondents about Existence of Research Culture in their Respective Colleges

\begin{tabular}{|c|c|c|c|c|c|c|}
\hline \multirow[t]{3}{*}{ Questions } & \multicolumn{6}{|c|}{ Responses of students } \\
\hline & \multicolumn{2}{|c|}{$\begin{array}{c}\text { GDC } \\
\text { Kishtwar }\end{array}$} & \multicolumn{2}{|c|}{$\begin{array}{c}\text { GDC } \\
\text { Ramban }\end{array}$} & \multicolumn{2}{|c|}{ GDC Doda } \\
\hline & No & Yes & No & Yes & No & Yes \\
\hline Did your teacher apply Discussion Method in the classroom & 100 & & 100 & & 100 & \\
\hline Did you use internet Facility in your College & - & & - & & - & \\
\hline Did you read any research related topic in your college course & - & & - & & - & \\
\hline Did you attended any conference/ seminar in your college & - & & - & & - & \\
\hline Did your teacher treat you friendly & - & & - & & - & \\
\hline Do you have first preference for university education & - & & - & & - & \\
\hline Were you satisfied with your teaching learning process & - & & - & & - & \\
\hline Did you read any research paper or article in your college life & - & & - & & - & \\
\hline Did you have student associations in your colleges & - & & - & & - & \\
\hline Did you have all permanent teaching staff & - & & - & & - & \\
\hline \multicolumn{7}{|l|}{ Did you read text books related to your syllabus in college life } \\
\hline \multirow[t]{2}{*}{ Questions } & \multicolumn{6}{|c|}{ Responses of Teachers } \\
\hline & No & Yes & No & Yes & No & Yes \\
\hline Do you organize any seminar/conference in your College & - & & - & & - & \\
\hline Have you got any Research Project in your college & - & & - & & - & \\
\hline Do you teach research related topics to your students & - & & - & & - & \\
\hline Have you guided any research student in the college & - & & - & & - & \\
\hline Do you conduct the field Survey to make the teaching empirical & - & & - & & - & \\
\hline Have you chosen the college teaching by choice & - & & - & & - & \\
\hline Are you presently engaged into any research work & - & & - & & - & \\
\hline Do you get equal pay for equal work & - & & - & & - & \\
\hline
\end{tabular}

Source: Field Survey (2016) 